\title{
Prognostic factors for disease-specific survival in 108 patients with Hürthle cell thyroid carcinoma: a single-institution experience
}

\author{
Rok Petric ${ }^{1 \dagger}$, Barbara Gazic ${ }^{2 \dagger}$ and Nikola Besic ${ }^{1 *}$
}

\begin{abstract}
Background: Hürthle cell thyroid carcinoma (HCTC) is a rare disease. It is believed that it is more aggressive than follicular thyroid carcinoma. The aim of our study was to identify factors associated with disease-specific and disease-free survival.

Methods: Altogether, 108 patients with HCTC (26 male, 82 female; median age 62 years; range 19-87 years) treated at our Institute from 1972 to 2011 were included in the present retrospective study. Data on age, clinical and histopathological factors, tumor stage, recurrence, disease-free and disease-specific survival were collected. Univariate analysis was used to identify factors associated with disease-specific survival. Cox's multivariate regression model was used to identify independent prognostic factors for disease-specific survival.

Results: The follow-up period was 1 to 337 (median 105) months. Of 108 patients, 12 (11\%) had distant and 8 (7\%) had locoregional metastases before primary treatment. Recurrence was diagnosed in 26 cases (24\%): locoregional, distant, and both locoregional and distant in 12,11, and 3 cases, respectively. The 5-year, 10-year, and 20-year disease-specific survival were $96 \%, 88 \%$, and $67 \%$, respectively. Independent prognostic factors for disease-specific survival were: age of patients at diagnosis, distant metastases and residual tumor after surgery.
\end{abstract}

Conclusion: Long disease-specific survival was found in patients with HCTC younger than 45 years of age without distant metastases and without residual tumor after surgery.

Keywords: Hürthle cell thyroid carcinoma, Surgery, Survival, Pathology

\section{Background}

Hürthle cell thyroid carcinoma (HCTC) is a rare type of thyroid carcinoma [1] which accounts for around $3 \%$ of all thyroid malignancies [2]. Only about 400 patients with HCTC were reported from 1935 to 2004 [1]. According to the World Health Organization classification [3], HCTC is considered an oxyphilic variant of follicular thyroid cancer (FTC), but genomic dissection of HCTC revealed a unique class of thyroid malignancy distinct from papillary and follicular thyroid cancer [4].

There are only few population-based studies [2,5-7] and many reports from single-institution studies of patients with HCTC [8-24]. Older studies reported poor

\footnotetext{
*Correspondence: nbesic@onko-i.si

${ }^{\dagger}$ Equal contributors

'Department of Surgery, Institute of Oncology Ljubljana, Ljubljana, Slovenia

Full list of author information is available at the end of the article
}

survival of patients with HCTC $[8,9,11-13]$, but patients were not treated in accordance with the current standard of care. Nagar et al. reported that survival in HCTC has improved dramatically over time in the United States and that survival rates for HCTC and FTC are currently the same [7]. Similarly, Bhattacharyya reported that overall survival for HCTC was similar to that of comparably staged FTC [2]. Unfortunately, they did not report on the treatment of patients, and they did not explain why survival of patients with HCTC has improved.

At our Institute, patients with HCTC have been treated over the last 40 years on the basis of the same principle, which is now standard treatment and is recommended by the ATA guidelines [25]. Our aim was to report a singleinstitution experience with a large number of patients with a long follow-up period. Another aim of the study was to

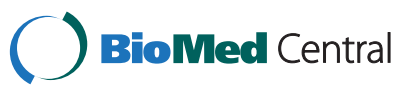

(c) 2014 Petric et al.; licensee BioMed Central Ltd. This is an Open Access article distributed under the terms of the Creative Commons Attribution License (http://creativecommons.org/licenses/by/4.0), which permits unrestricted use, distribution, and reproduction in any medium, provided the original work is properly credited. The Creative Commons Public Domain Dedication waiver (http://creativecommons.org/publicdomain/zero/1.0/) applies to the data made available in this article, unless otherwise stated. 
determine which factors are predictive of recurrence and disease-specific survival in HCTC.

\section{Methods}

\section{Patients}

A total of 108 patients with HCTC (82 women, 26 men; age 19 to 87 years, median age 62 years, mean age 58 years) were treated at our Institute between 1975 and 2007 and were included in our retrospective study. The follow-up time was 1-337 (median 105, mean 117) months.

The Medical Ethics Committee of the Republic Slovenia and the Protocol Review Board and Ethics Committee of the Institute of Oncology Ljubljana reviewed and approved the study, which was performed in accordance with the ethical standards laid down in an appropriate version of the 1964 Declaration of Helsinki.

All histological slides were examined by the pathologist (B.G.) experienced in thyroid pathomorphology. A diagnosis of HCTC was made based on histological criteria defined by LiVolsi and Rosai [26,27]. Only lesions demonstrating more than $75 \%$ of follicular cells with oncocytic characteristics were included in the study group. The identification of a cell as an oncocyte was based on the presence of acidophilic, granular cytoplasm and hyperchromatic or vesicular nuclei with large nucleolus. The diagnosis of malignancy was based on histological evidence of transcapsular and/or vascular invasion, extrathyroidal local tissue invasion by primary tumor [26,27], or presence of nodal or distant metastasis. All patients with Hürthle cell neoplasms with cells containing typical nuclear features of papillary carcinoma were excluded from our present study and were the subject of one of our previous studies [28].

A chart review was performed, and data on patients' age, clinical and histopathological factors, tumor stage, treatment, recurrence, disease-free and disease-specific survival were collected. Clinical and pathomorphological characteristics are given in Table 1.

Patients were categorized into two groups: less than 45 years of age and 45 years or older. Tumor size, presence of regional and/or distant metastases, as well as residual tumor after surgery were assessed by the TNM clinical classification system according to the UICC criteria from 2009 [29]. In addition to chest X-ray, the diagnostic work-up also included ultrasound (US) of the thyroid gland and determination of serum thyroglobulin ( $\mathrm{Tg}$ ) concentration. Additional diagnostic work-up (computed tomography $[\mathrm{CT}]$, magnetic resonance imaging [MRI], bone scintigraphy and/or PET-CT) was performed whenever medical history or physical examination indicated distant metastases. After thyroid surgery, additional diagnostic work-up was performed if radioactive iodine (RAI) uptake was detected outside the thyroid bed, or if the thyroglobulin $(\mathrm{Tg})$ level was greater than $1 \mathrm{ng} / \mathrm{mL}$.
Follow-up was performed at our Institute at least once a year. It consisted of a medical history, physical examination and determination of serum Tg concentration. Criteria for disease-free survival were: $\mathrm{Tg}$ levels of less than $1 \mathrm{ng} / \mathrm{mL}$, negative whole-body RAI scans, and exclusion of cervical lymph node metastases detected by US $[25,30]$. Whenever Tg concentration was elevated or clinical symptoms of possible recurrence were present, imaging (X-ray, US, CT, MR, bone scintigraphy, PET-CT and/or RAI scintigraphy) was performed in order to determine the site and extent of suspected recurrence.

\section{Treatment}

Our patients were treated by different surgeons. Therefore, surgical treatment of primary tumor, locoregional recurrences, and distant metastases was not uniform; neither was the proportion of patients treated by RAI ablation of thyroid remnant, external beam radiotherapy (EBRT), chemotherapy, and RAI therapy.

Surgery is the mainstay of the treatment of HCTC. Among surgically-treated patients, $79 \%$ had primary surgery at the Institute of Oncology and 21\% elsewhere (some of them had either biopsy alone or some kind of inadequate surgery). Completion thyroidectomy was performed in 20 patients. All other specific therapies (surgery, RAI, EBRT and/or chemotherapy) as well as follow-up were performed in all patients at the Institute of Oncology.

Total or near-total thyroidectomy is considered an adequate surgical procedure for HCTC. Our treatment approach after an inadequate surgical procedure is generally completion thyroidectomy. However, completion thyroidectomy was not performed if there were technical problems (e.g. recurrent nerve injury or hypoparathyroidism or severe fibrosis), or if the patient refused another surgical procedure or preferred treatment with RAI. Initial treatment in 13 patients with locally advanced tumor was neoadjuvant chemotherapy, while one patient received concomitant EBRT with a tumor dose of 36 Gy. Tumor size decreased in all these patients, and in 43\%, the largest tumor size decreased by more than $50 \%$ [31]. The data on the type of surgery for primary tumors are listed in Table 1. Altogether 16 patients had pT4 tumor and 9 patients had an R2 tumor resection. After surgical procedures macroscopic tumor was present on the trachea in 6 cases, the esophagus in 4 cases, the larynx in 2 cases, the carotid artery in 2 cases, mediastinal vessels in 2 cases, recurrent laryngeal nerve in 1 cases and the prevertebral fascia in 1 case. None of our patients required total laryngectomy or any other radical procedure. Infiltration of trachea was managed surgically by tracheal shaving, and in one case, by tracheostomy.

Metastases in regional lymph nodes were treated surgically by modified radical neck dissection in nine patients; 
Table 1 Patients' and tumor characteristics and univariate statistical analysis of disease-specific survival

\begin{tabular}{|c|c|c|c|c|c|}
\hline Factor & Subgroup & Patients number (\%) & $\begin{array}{l}\text { Dead of disease } \\
\qquad(\mathrm{N}=20)\end{array}$ & $\begin{array}{c}\text { Alive or dead of } \\
\text { other causes }(\mathrm{N}=88)\end{array}$ & $p$-value \\
\hline \multirow[t]{2}{*}{ Gender } & Female & $82(76)$ & 12 & 70 & 0.08 \\
\hline & Male & $26(24)$ & 8 & 18 & \\
\hline \multirow[t]{2}{*}{ Age (years) } & 44 or less & $23(21)$ & 0 & 23 & 0.006 \\
\hline & 45 or more & $85(79)$ & 20 & 65 & \\
\hline \multirow[t]{2}{*}{ Tumor diameter $(\mathrm{cm})$} & $0-4$ & $56(52)$ & 2 & 54 & 0.001 \\
\hline & 4.01 and more & $52(48)$ & 18 & 34 & \\
\hline \multirow[t]{5}{*}{ pT tumor stage } & pTx & $1(1)$ & 1 & 0 & 0.001 \\
\hline & pT1 & $9(8)$ & 0 & 9 & \\
\hline & pT2 & $35(32)$ & 1 & 34 & \\
\hline & pT3 & $47(43)$ & 9 & 38 & \\
\hline & pT4 & $16(15)$ & 9 & 7 & \\
\hline \multirow[t]{4}{*}{$\mathrm{N}$ stage } & No & $100(93)$ & 16 & 84 & 0.04 \\
\hline & $\mathrm{N} 1(\mathrm{~N} 1 \mathrm{a}+\mathrm{N} 1 \mathrm{~b})$ & $8(7)$ & 4 & 4 & \\
\hline & $\mathrm{N} 1 \mathrm{a}$ & 3 & & & \\
\hline & $\mathrm{N} 1 \mathrm{~b}$ & 5 & & & \\
\hline \multirow[t]{2}{*}{ M stage } & Mo & $96(89)$ & 11 & 85 & 0.001 \\
\hline & M1 & $12(11)$ & 9 & 3 & \\
\hline \multirow[t]{2}{*}{ Tumor differentiation } & Well & $66(61)$ & 8 & 58 & 0.03 \\
\hline & Moderate or poor & $36+6(33+6)$ & 12 & 30 & \\
\hline \multirow[t]{2}{*}{ Vascular invasion } & Minimal or suspected & $66(61)$ & 10 & 56 & 0.26 \\
\hline & Extensively & $42(39)$ & 10 & 32 & \\
\hline \multirow[t]{2}{*}{ Capsular invasion } & No or minimal & $56(52)$ & 8 & 48 & 0.24 \\
\hline & Transcapsular & $52(48)$ & 12 & 40 & \\
\hline \multirow[t]{2}{*}{ Thyroid surgical procedure } & Total or near-total thyroidectomy & $77(71)$ & 8 & 69 & 0.001 \\
\hline & Lobectomy or less & $31(29)$ & 12 & 19 & \\
\hline \multirow[t]{3}{*}{ Residual tumor after surgery } & RO - without residual tumor & $80(74)$ & 7 & 73 & 0.001 \\
\hline & R1 - microscopic residual tumor & $19(17)$ & 10 & 9 & \\
\hline & R2- macroscopic residual tumor & $9(8)$ & 3 & 6 & \\
\hline \multirow[t]{2}{*}{ Neck dissection } & No & $99(92)$ & 15 & 84 & 0.01 \\
\hline & Yes & $9(8)$ & 5 & 4 & \\
\hline \multirow[t]{2}{*}{ Radioiodine ablation after surgery } & No & $21(20)$ & 5 & 16 & 0.53 \\
\hline & Yes & $87(80)$ & 15 & 72 & \\
\hline \multirow[t]{2}{*}{ Therapy with radioiodine } & No & $77(71)$ & 3 & 29 & 0.17 \\
\hline & Yes & $31(29)$ & 17 & 59 & \\
\hline \multirow[t]{2}{*}{ External beam radiotherapy } & No & $85(79)$ & 11 & 74 & 0.004 \\
\hline & Yes - neck and mediastinum & $23(21)$ & 9 & 14 & \\
\hline \multirow[t]{2}{*}{ External beam radioterapy } & No & $81(75)$ & 6 & 75 & 0.001 \\
\hline & Yes - any site & $27(25)$ & 14 & 13 & \\
\hline \multirow[t]{2}{*}{ Chemotherapy } & No & $92(85)$ & 11 & 81 & 0.001 \\
\hline & Yes & $16(15)$ & 9 & 7 & \\
\hline
\end{tabular}


Table 1 Patients' and tumor characteristics and univariate statistical analysis of disease-specific survival (Continued)

\begin{tabular}{|c|c|c|c|c|c|}
\hline \multirow[t]{5}{*}{ Recurrence } & No & $70(65)$ & 0 & 70 & - \\
\hline & Yes - distant & $11(10)$ & 4 & 7 & \\
\hline & Yes - locoregional & $12(11)$ & 5 & 7 & \\
\hline & Yes - locoregional and distant & $3(3)$ & 2 & 1 & \\
\hline & Initially distant metastases & $12(11)$ & 9 & 3 & \\
\hline \multirow[t]{5}{*}{ Outcome } & Alive without disease & $52(48)$ & 0 & 52 & - \\
\hline & Alive with disease & $16(15)$ & 0 & 16 & \\
\hline & Dead of disease & $20(19)$ & 20 & 0 & \\
\hline & Dead of other causes & $15(14)$ & 0 & 15 & \\
\hline & Lost to follow-up & $5(5)$ & 0 & 5 & \\
\hline
\end{tabular}

in seven as part of primary treatment and in two because of disease recurrence. Levels 2-6 and levels 2-5 were removed in five and four cases, respectively.

RAI was used for the ablation of thyroid remnant tissue in 87 patients (80\%) treated with surgery. The ablation dose was 2.98-3.7 GBq (80-100 $\mathrm{mCi})$ of RAI. After surgery, all patients received L-thyroxine therapy for thyrotropin (TSH) suppression. RAI was used also for the treatment of distant metastases and inoperable locoregional recurrences. Patients with distant metastases underwent total thyroidectomy prior to RAI treatment in order to increase the uptake of iodine in metastases and to speed up treatment. Before 2002, the serum concentration of $\mathrm{TSH}$ of $>30 \mathrm{mU} / \mathrm{L}$ had been achieved by a 4-6-week withdrawal of L-thyroxine suppression therapy. Since 2002, recombinant human TSH (rhTSH)-aided RAI therapy has been used in elderly patients with concomitant diseases, a history of severe hypothyroid or compressive symptoms and/or evidence of tumor progression during thyroid hormone withdrawal [32].

Sixteen of our patients with locoregionally advanced and/or metastatic disease were treated with chemotherapy. Targeted therapy was not used in patients included in the present report. EBRT was done in a total of $27 \mathrm{pa}-$ tients, of whom 23 received EBRT to the neck and superior mediastinum.

\section{Survival}

Disease-specific survival was defined as the period from the first day of primary treatment (surgery, chemotherapy, external irradiation, or radioactive iodine) to death of HCTC or the last follow-up. Overall survival was defined as the period from the first day of primary treatment (surgery, chemotherapy, external irradiation, or radioactive iodine) to death of any cause or the last follow-up.

Disease-free survival was defined as the period from the first day of primary treatment (surgery, chemotherapy, external irradiation, or radioactive iodine) to the radiologic or morphologic diagnosis of recurrence or the last followup. Only lymph node metastases were considered as regional recurrence. The median duration of follow-up was 8.75 years (range 0.1-28.1 years).

\section{Statistical analysis}

Univariate analysis was used to identify factors associated with disease-free and disease-specific survival. Disease-specific survival and disease-free interval were compared by log-rank test. All comparisons were twosided, and a p-value of $<0.05$ was considered statistically significant. Survival curves were calculated according to the Kaplan-Meier method. Cox's multivariate regression model was used to identify independent prognostic factors of disease-free and disease-specific survival. For statistical analysis, the statistical package PASW 18 (SPSS Inc., Chicago, IL, USA) was used.

\section{Results}

One hundred eight patients were confirmed as having HCTC at the Institute of Oncology Ljubljana between 1972 and 2011, with a female-to-male ratio of 3.2:1. The median age at diagnosis was 62 years (range 19-87 years).

Tumor diameter ranged from 1 to $18 \mathrm{~cm}$ (median $4 \mathrm{~cm}$ ). Many tumors were locally advanced at presentation. Extrathyroid tumor growth was present in 24 patients (22\%) and lymph node metastases were found in 8 patients $(7 \%)$. Metastatic lymph nodes were found in level 2 in 3 cases, level 3 in 5 cases, level 4 in 4 cases, level 5 in 1 case and level 6 in 2 cases. Distant metastases before therapy were present in 12 patients (11\%), and all of these were single-organ metastases. Considering the site of metastatic spread, the lungs were involved in 8 patients, the skeleton in 3 cases, and the kidneys in one patient.

\section{Disease-free survival}

Recurrence was diagnosed in 26 cases: locoregional, distant, and both locoregional and distant in 12, 11, and 3 cases, respectively. The 5-year, 10-year, and 20-year disease-free intervals were $78 \%, 68 \%$, and $65 \%$, respectively. After surgical therapy of locoregional recurrence, 
six patients had been without evidence of disease for $0.5-20$ years (median 4 years).

Univariate analysis (Table 2) showed that ten factors were associated with disease-free survival $(p<0.05)$. All factors that showed statistical correlation $(\mathrm{p}<0.05$ or less) with duration of survival and treatment-related factors were included in the multivariate analysis. Independent prognostic factors for disease-free survival were: gender, age of patients, regional metastases, and residual tumor after surgery. Relative risks of disease-free survival of subgroups are shown in Table 3. Shorter disease-free survival was 2.97 times more likely in men compared to women. Shorter disease-free survival was 17.04 times more likely in patients older than 45 years of age than in younger patients and 7.56 times more likely in patients with regional metastases than in patients without regional metastases. Shorter disease-free survival was 5.05 and 1.24 times more likely in patients with macroscopic and microscopic residual tumor than in patients without residual disease, respectively.

\section{Disease-specific survival}

Disease-specific survival of our patients ranged from 0.1 to 28 years. The 5-year, 10-year, and 20-year diseasespecific survival were $96 \%, 88 \%$, and $67 \%$, respectively.

By the end of the study, 68 patients were still alive (52 had no evidence of disease, 16 were alive with disease), 5 patients were lost to follow-up, 15 patients died of causes unrelated to primary disease, while 20 patients died of thyroid carcinoma. Of the latter, 18 patients died of distant metastases, and the remaining 2 patients both died of distant and locoregional progression of the disease.

Univariate analysis (Table 1) showed that eleven factors were associated with disease-specific survival $(\mathrm{p}<$ $0.05)$. All factors that showed statistically univariate correlation ( $\mathrm{p}<0.05$ or less) with duration of survival and treatment-related factors were included in the multivariate analysis. Independent prognostic factors for diseasespecific survival were $(\mathrm{p}<0.001)$ : age of patients (Figure 1$)$, distant metastases (Figure 2), and residual tumor after surgery (Figure 3 ).

The 10-year survival of our patients without distant metastases at presentation was $92 \%$, while in those with distant metastases it was $60 \%$. Patients with initial metastases survived 0.1-16.75 years (median 11.75 years). The survival of eight patients with initial lung metastases was 3.4-16.75 years (median 11.75 years).

\section{Discussion}

There are only a limited number of publications about prognostic factors for disease-specific survival in patients with HCTC from different single institutions $[1,2,6,7,9,11,14,15,17,19,23]$. In these publications, 20 different prognostic factors were reported. Prognostic factors were related to: patient's characteristics $[6,19]$, tumor $[6,9,11,17,19,23]$, extent of disease $[1,6,9,17,19,23]$ and treatment $[1,6,19,23]$. The majority of series included only a very limited number of patients, therefore the authors of these studies could perform only univariate statistical analysis. To our knowledge, so far only six publications $[1,2,6,11,19,23]$ have reported the results of multivariate regression analysis of prognostic factors for diseasespecific survival in patients with HCTC. The following prognostic factors were reported: age of patients $[2,6]$, gender [2], marital status [6], tumor size [2,6,17], extrathyroidal invasion $[2,6,19]$, tumor stage [23], regional metastases [23], distant metastases [6,19], capsular invasion [11], multifocal disease [19], solid pattern of growth [11], and extent of surgery [23]. In our patients, the independent prognostic factors for disease-specific survival were: age of patients, distant metastases, and residual tumor after surgery. Two of the previous six papers were population-based $[2,6]$, while two were clinicopathologic [11,17]. To continue, two papers reported data from major cancer comprehensive centers covering large populations [19,23]. However, both of them included a smaller number of patients than our study, therefore our paper provides more robust data on a larger number of prognostic factors.

The mean age of our patients at diagnosis was 58 years, which is in accordance with the majority of reports in the literature $[1,6,10,14,15,23]$. Our results confirm the findings in the literature $[2,6,17]$ and show that patients' age is an independent prognostic factor for both diseasespecific survival and disease-free interval. In patients younger than 45 years of age, shorter disease-free survival was as many as 17.04 times more likely than in older patients.

Distant metastases were an independent prognostic factor for disease-specific survival in our patients. In patients with distant metastases, the risk of shorter survival was 3.3 times higher than in patients without distant dissemination. This relative risk was 5.3 in the study of Lopez-Penabad et al. [19].

Residual tumor after surgery was another independent prognostic factor for disease-specific survival in our population of patients. Our multivariate analysis also included the following confounding factors related to locoregional tumor extension and treatment: tumor size, tumor stage, regional metastases, capsular invasion, extrathyroidal invasion, and extent of surgery.

The recurrence rate in our patients was $27 \%$, which is comparable to reports in the literature $[1,17,19,23]$. Khafif et al. reported that locoregional recurrence occurred in only 4 of 42 patients (10.5\%) [14]. The probable cause for their low recurrence rate is the obvious difference in patient selection between our and their 
Table 2 Univariate statistical analysis of disease-free survival

\begin{tabular}{|c|c|c|c|c|}
\hline Factor & Subgroup & Without recurrence $(\mathrm{N}=70)$ & With recurrence $(N=26)$ & p-value \\
\hline \multirow[t]{2}{*}{ Gender } & Female & 59 & 14 & 0.001 \\
\hline & Male & 11 & 12 & \\
\hline \multirow[t]{2}{*}{ Age (years) } & 44 or less & 20 & 1 & 0.03 \\
\hline & 45 or more & 50 & 25 & \\
\hline \multirow[t]{2}{*}{ Tumor diameter (cm) } & $0-4$ & 44 & 11 & 0.10 \\
\hline & 4.01 and more & 26 & 15 & \\
\hline \multirow[t]{3}{*}{ pT tumor stage } & pTx, pT1 or pT2 & 38 & 5 & 0.001 \\
\hline & pT3 & 28 & 13 & \\
\hline & pT4 & 4 & 8 & \\
\hline \multirow[t]{2}{*}{ N stage } & No & 68 & 22 & 0.049 \\
\hline & N1 & 2 & 4 & \\
\hline \multirow[t]{2}{*}{ M stage } & MO & 70 & 26 & - \\
\hline & M1 & 0 & 0 & \\
\hline \multirow[t]{2}{*}{ Tumor differentiation } & Well & 48 & 13 & 0.06 \\
\hline & Moderate or poor & 22 & 13 & \\
\hline \multirow[t]{2}{*}{ Vascular invasion } & Minimal or suspected & 47 & 16 & 0.47 \\
\hline & Extensively & 23 & 10 & \\
\hline \multirow[t]{2}{*}{ Capsular invasion } & No or minimal & 34 & 16 & 0.34 \\
\hline & Transcapsular & 36 & 10 & \\
\hline \multirow[t]{2}{*}{ Thyroid surgical procedure } & Total or near-total thyroidectomy & 55 & 16 & 0.05 \\
\hline & Lobectomy or less & 15 & 10 & \\
\hline \multirow[t]{3}{*}{ Residual tumor after surgery } & Ro - without residual tumor & 62 & 15 & 0.005 \\
\hline & R1 - microscopic residual tumor & 5 & 6 & \\
\hline & R2- macroscopic residual tumor & 3 & 5 & \\
\hline \multirow[t]{2}{*}{ Neck dissection } & No & 70 & 22 & 0.005 \\
\hline & Yes & 0 & 4 & \\
\hline \multirow[t]{2}{*}{ Radioiodine ablation } & No & 16 & 3 & 0.26 \\
\hline & Yes & 54 & 23 & \\
\hline \multirow[t]{2}{*}{ Therapy with radioiodine } & No & 65 & 12 & 0.001 \\
\hline & Yes & 5 & 14 & \\
\hline \multirow[t]{2}{*}{ External beam radiotherapy } & No & 62 & 17 & 0.01 \\
\hline & Yes - neck and mediastinum & 8 & 9 & \\
\hline \multirow[t]{2}{*}{ External beam radiotherapy } & No & 64 & 15 & 0.001 \\
\hline & Yes - any site & 6 & 11 & \\
\hline \multirow[t]{2}{*}{ Chemotherapy } & No & 66 & 22 & 0.11 \\
\hline & Yes & 4 & 4 & \\
\hline \multirow[t]{5}{*}{ Outcome } & Alive without disease & 52 & 0 & - \\
\hline & Alive with disease & 0 & 14 & \\
\hline & Dead of disease & 0 & 11 & \\
\hline & Dead of other causes & 14 & 1 & \\
\hline & Lost to follow-up & 4 & 0 & \\
\hline
\end{tabular}


Table 3 Multivariate analysis of disease-free survival

\begin{tabular}{llccc}
\hline Factor & Subgroup & Odds ratio & $\begin{array}{c}\text { Odds ratio } \\
(\mathbf{9 5 \%} \mathbf{C l})\end{array}$ & p-value \\
\hline Gender & Female & 1 & 1 & 0.013 \\
& Male & 2.97 & $1.25-7.04$ & \\
Age (years) & 44 or less & 1 & 1 & 0.007 \\
& 45 or more & 17.04 & $2.19-132.46$ & \\
N stage & N0 & 1 & 1 & 0.001 \\
& N1 & 7.56 & $2.26-25.27$ & \\
Residual tumor & R0 & 1 & 1 & 0.04 \\
after surgery & R1 & 1.24 & $0.36-4.23$ & 0.726 \\
& R2 & 5.05 & $1.66-15.38$ & 0.04 \\
\hline
\end{tabular}

The likelihood of malignancy as calculated by logistic regression (model summary: chi-square $=44.596 ; 5$ degrees of freedom; $P=0.0001 ;-2 \log$ likelihood of 177.131).

study groups. Their patients received primarily private consultations with only two surgeons. Therefore, HCTC was usually diagnosed at an earlier stage [14]. On the other hand, our patients had a lower recurrence rate compared to patients from another two tertiary cancer comprehensive centers: Royal Marsden Hospital and Sloan-Kettering Cancer Center, with the recurrence rate of $34 \%$ and $43 \%$, respectively [23,17]. Possibly, the lower recurrence rate in our patients was related to more frequent use of adjuvant multimodal therapy.

The 10-year disease-free survival was $68 \%$ in our patients, while it was reported to be $40.5 \%, 43 \%$, and $61 \%$ by Kushcayeva et al. [1], Mills et al. [23], and Stojadinovic

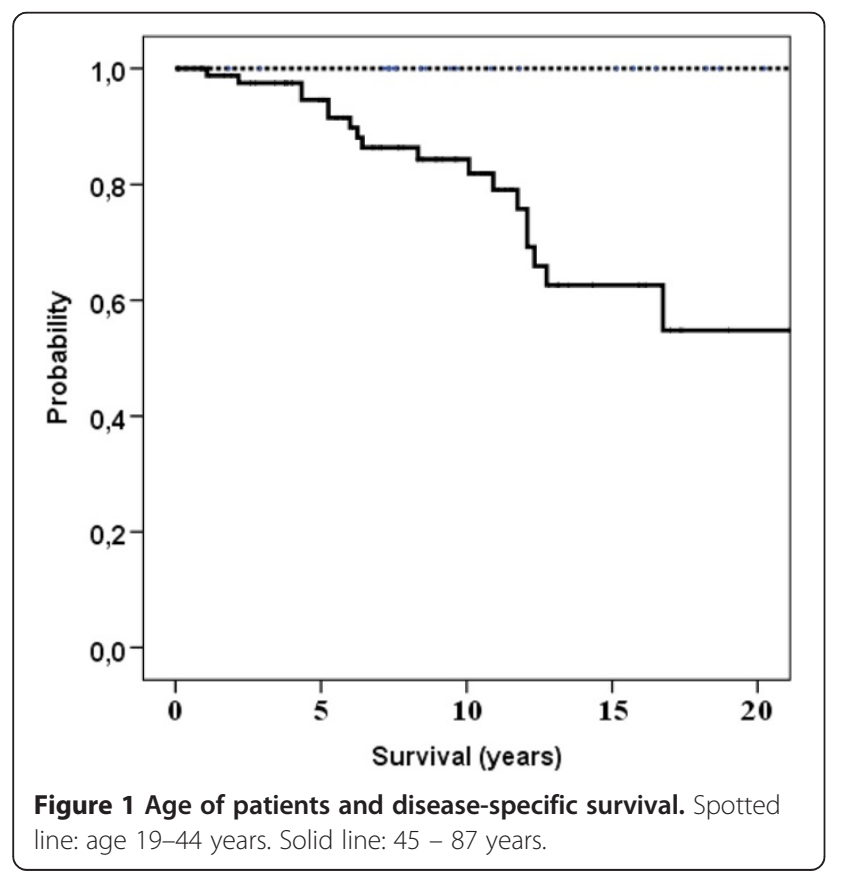

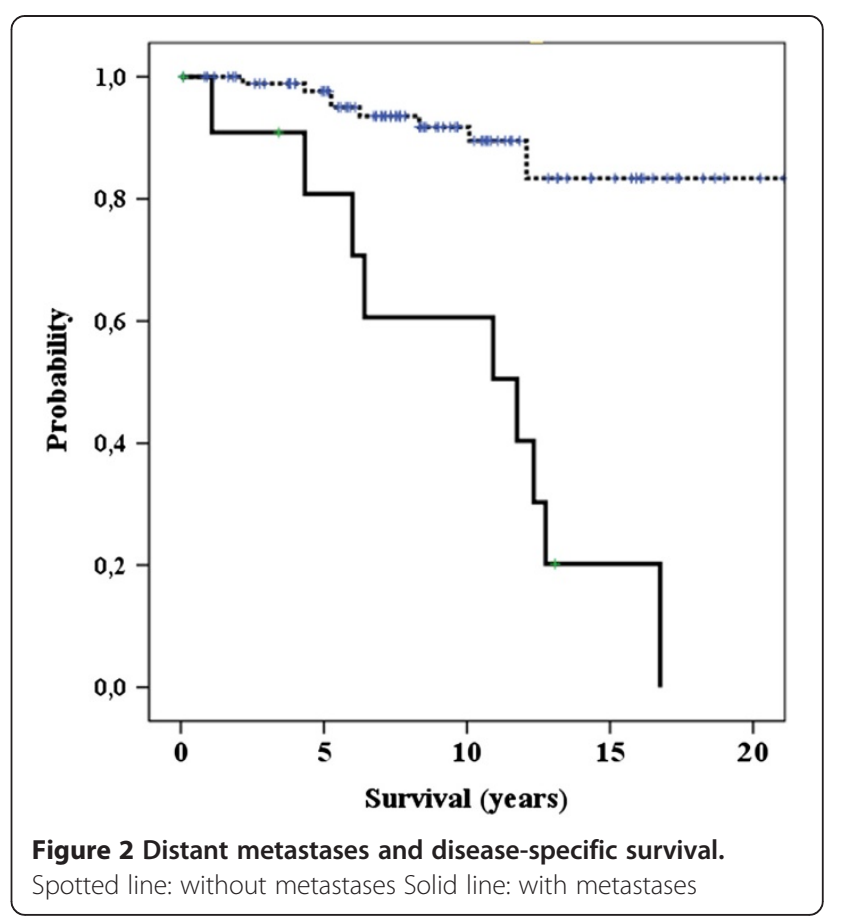

et al. [17], respectively. To our knowledge, only six reports $[1,14,15,17,22,23]$ were published about disease-free survival and 15 factors were found to correlate with recurrence of HCTC. Predictive factors were related to: patient's characteristics [1], tumor [14,15,17,22], extent of disease $[1,15,17,23]$ and treatment $[1,23]$. However, the majority of previous papers had a small number of



Figure 3 Residual tumor after surgery and disease-specific survival. Spotted line: R0 resection. Dotted line: R1 resection. Solid line $\mathrm{R} 2$ resection. 
patients, and only two publications $[15,23]$ reported the results of multivariate logistic regression analysis of the disease-free interval in patients with HCTC. Our multivariate analysis showed that independent prognostic factors for disease-free survival were: gender, age of patients, regional metastases, and residual tumor after surgery. Regional metastases have already been a known independent prognostic factor from the study of Stojadinovic et al. [15]. Extrathyroidal invasion was another independent prognostic factor in their study [15]. However, in our study group, extrathyroidal invasion was a prognostic factor by univariate analysis only and was not an independent factor, while residual tumor after surgery was an independent prognostic factor. Furthermore, an old clinical observation that younger patients and females have a favorable prognosis was statistically proven by our results.

The 10-year disease-specific survival in our patients was $88 \%$, while it was $49 \%, 64 \%$, and $73 \%$ in studies reported by Kushcayeva et al. [1], Mills et al. [23], and Stojadinovic et al. [17], respectively. It should be stressed that survival rates represent the result of both selection bias, i.e. more advanced disease in larger tertiary centers, and the effectiveness of different treatment modalities used in patients. Fortunately, SEER [6] and our data show that nowadays the majority of patients with HCTC have a favorable prognosis. Total thyroidectomy and RAI ablation of thyroid remnant tissue enable early detection of tumor recurrence. Furthermore, it is possible that such treatment affects disease-free and disease-specific survival. In addition, our results also show that long-term survival can be obtained also in patients with locoregionally advanced and metastatic disease, if they are treated multidisciplinary. Chemotherapy before surgical procedure may be effective in order to decrease the tumor size in HCTC [31]. Our group reported that RAI therapy may be effective in patients with metastatic HCTC [18] and that recombinant human thyrotropin-aided RAI therapy may be effective in patients with metastatic HCTC [32]. Since residual tumor after thyroid surgery is an independent prognostic factor for disease-specific as well as disease-free survival, an effective locoregional therapy is mandatory. Therefore, EBRT should be used in cases of residual tumor.

The limitation of our study is that the results of treatment and survival are reported only from a single institution. Another limitation is that not all our patients were treated uniformly because during a 40-year time frame, they were treated by many surgeons and oncologists. Our study is observational and not randomized, thus it is not possible to draw conclusions about the impact of treatment on patients' survival. However, the advantage of our study is that it included all patients with HCTC from Slovenia treated in the period from 1972 to 2011. During this period, all patients with thyroid carcinoma were referred to the only tertiary referral center for postoperative treatment and follow-up of patients with thyroid carcinoma in our country. Thus, our data are more comparable to the study reported by Goffredo et al. [6], a population-level analysis of 3,311 patients from the Surveillance, Epidemiology, and End Results (SEER) database from 1988 to 2009 in the USA, than to reports from cancer comprehensive centers. Patients with more advanced disease are more often treated in these centers than in community hospitals $[9,11,15,17,19,22-24]$. Goffredo et al. [6] reported that the female-to-male ratio was 3.22:1, mean age of patients was 58 years, mean tumor size was $3.6 \mathrm{~cm}$, and extrathyroid extension was present in $14 \%$ of cases. Initially, only $5 \%$ of their patients had regional and 5\% distant metastases. However, our patients had more advanced disease: mean tumor size was $5 \mathrm{~cm}$, extrathyroid extension was present in $22 \%$ of cases, $7 \%$ of patients had regional and $11 \%$ distant metastases. Probably, our patients had more advanced disease because Slovenia is an endemic goiter region [33]. However, our patients had similar 10-year disease-specific survival compared to the SEER database patients reported by Goffredo et al. [6]. This can be explained by more effective treatment of our patients. Total thyroidectomy enables more effective adjuvant treatment with different modalities (radioactive iodine, EBRT and/or chemotherapy) resulting in longer survival, which is particularly important in patients with more advanced HCTC. Total thyroidectomy, RAI ablation of the thyroid remnant, and EBRT were done in Goffredo's [6] and our patients in $75 \%, 45 \%$ and $4 \%$, and $71 \%, 87 \%$ and $27 \%$, respectively.

\section{Conclusion}

Independent prognostic factors for disease-specific survival were: age of patients, distant metastases, and residual tumor after surgery. Independent prognostic factors for disease-free survival were: gender, age of patients, regional metastases, and residual tumor after surgery.

\section{Consent}

Written informed consent was obtained from the patient for the publication of this report and any accompanying images.

\section{Competing interests}

The authors declare that they have no competing interests.

\section{Authors' contributions}

RP participated in the design of the study, partially collected data and performed the statistical analysis and drafted manuscript. NB participated in design of the study and drafted the manuscript. BG reviewed slides. All authors read and approved the final manuscript.

\section{Acknowledgements}

The paper was supported by a research program, P3-0289, by the Ministry of Higher Education, Science and Sport of Slovenia. 


\section{Author details}

'Department of Surgery, Institute of Oncology Ljubljana, Ljubljana, Slovenia. 2Department of Pathology, Institute of Oncology Ljubljana, Ljubljana, Slovenia.

Received: 19 June 2014 Accepted: 17 October 2014 Published: 23 October 2014

\section{References}

1. Kushchayeva Y, Duh Q-Y, Kebebew E, Clark OH: Prognostic indications for Hürthle cell cancer. World J Surg 2004, 28:1266-1270.

2. Bhattacharyya N: Survival and prognosis in Hürthle cell carcinoma of the thyroid gland. Arch Otolaryngol Head Neck Surg 2003, 129:207-210.

3. Hedinger C, Williams ED, Sobin LH: The WHO histological classification of thyroid tumors: A commentary on the second edition. Cancer 1989, 63:908-911.

4. Ganly I, Ricarte Filho J, Eng S, Ghossein R, Morris LG, Liang Y, Socci N, Kannan K, Mo Q, Fagin JA, Chan TA: Genomic dissection of Hurthle cell carcinoma reveals a unique class of thyroid malignancy. $J$ Clin Endocrinol Metab 2013, 98:E962-E972.

5. Kuo EJ, Roman SA, Sosa JA: Patients with follicular and Hurthle cell microcarcinomas have compromised survival: a population level study of 22,738 patients. Surgery 2013, 154:1246-1254.

6. Goffredo P, Roman SA, Sosa JA: Hurthle cell carcinoma: a population-level analysis of 3311 patients. Cancer 2013, 119:504-511.

7. Nagar S, Aschebrook-Kilfoy B, Kaplan EL, Angelos P, Grogan RH: Hurthle cell carcinoma: an update on survival over the last 35 years. Surgery 2013, 154:1263-1271.

8. Thompson NW, Dunn EL, Batsakis JG, Nishiyama RH: Hürthle cell lesions of the thyroid gland. Surg Gynecol Obstet 1974, 139:555-560.

9. Watson RG, Brennan MD, Goellner JR, van Heerden JA, McConahey WM Taylor WF: Invasive Hürthle cell carcinoma of the thyroid: natural history and management. Mayo Clin Proc 1984, 59:851-855.

10. Har-El G, Hadar T, Segal K, Levy R, Sidi J: Hurthle cell carcinoma of the thyroid gland: a tumor of moderate malignancy. Cancer 1986, 57:1613-1617.

11. Carcangiu ML, Bianchi S, Savino D, Voynick IM, Rosai J: Follicular Hürthle cell tumors of the thyroid gland. Cancer 1991, 68:1944-1953.

12. Caplan RH, Abellera RM, Kisken WA: Hürthle cell neoplasms of the thyroid gland: Reassessment of functional capacity. Thyroid 1994, 4:243-248.

13. McDonald MP, Sanders LE, Silverman ML, Chan HS, Buyske J: Hürthle cell carcinoma of the thyroid gland: prognostic factors and results of surgical treatment. Surgery 1996, 120:1000-1005.

14. Khafif A, Khafif RA, Attie JN: Hürthle cell carcinoma: a malignancy of low-grade potential. Head Neck 1999, 21:506-511.

15. Stojadinovic A, Ghossein RA, Hoos A, Urist MJ, Spiro RH, Shah JP, Brennan MF Shaha AR, Singh B: Hürthle cell carcinoma: a critical histopathological appraisal. J Clin Oncol 2001, 19:2616-2625.

16. Sugino K, Ito K, Mimura T, Kameyama K, Iwasaki H, Ito K: Hürthle cell tumor of thyroid: Analysis of 188 cases. World J Surg 2001, 25:1160-1163.

17. Stojadinovic A, Hoos A, Ghossein RA, Urist MJ, Leung DH, Spiro RH, Shah JP, Brennan MF, Singh B, Shaha AR: Hürthle cell carcinoma: a 60-year experience. Ann Surg Oncol 2002, 9:197-203.

18. Besic N, Vidergar-Kralj B, Frkovic-Grazio S, Movrin-Stanovnik T, Auersperg M: The role of radioactive iodine in the treatment of Hürthle cell carcinoma of the thyroid. Thyroid 2003, 13:577-584.

19. Lopez-Penabad L, Chiu AC, Hoff AO, Schultz P, Gaztambide S, Ordoñez NG, Sherman SI: Prognostic factors in patients with Hürthle cell neoplasms of the thyroid. Cancer 2003, 97:1186-1194.

20. Foote RL, Brown PD, Garces YI, Mclver B, Kasperbauer JL: Is there a role for radiation therapy in the management of Hürthle cell carcinoma? Int $J$ Radiat Oncol Biol Phys 2003, 56:1067-1072.

21. Paunovic I, Krgovic K, Tatic S, Diklic A, Zivaljevic V, Kalezic N, Havelka M: Surgery for thyroid Hürthle cell tumours - a single institution experience. Eur J Surg Oncol 2006, 32:458-61.

22. Ghossein RA, Hiltzik DH, Carlson DL, Patel S, Shaha A, Shah JP, Tuttle RM, Singh B: Prognostic factors of recurrence in encapsulated Hurthle cell carcinoma of the thyroid gland: a clinicopathologic study of 50 cases. Cancer 2006, 106:1669-1676.

23. Mills SC, Haq M, Smellie WJ, Harmer C: Hürthle cell carcinoma of the thyroid: retrospective review of 62 patients treated at the Royal Marsden Hospital between 1946 and 2003. Eur J Surg Oncol 2009, 35:230-234.
24. Bishop JA, Wu G, Tufano RP, Westra WH: Histological patterns of locoregional recurrence in Hürthle cell carcinoma of the thyroid gland. Thyroid 2012, 22:690-694

25. Cooper DS, Doherty GM, Haugen BR, Kloos RT, Lee SL, Mandel SJ, Mazzaferri EL, Mclver B, Pacini F, Schlumberger M, Sherman SI, Steward DL, Tuttle RM: Revised American Thyroid Association management guidelines for patients with thyroid nodules and differentiated thyroid cancer. Thyroid 2009, 19:1167-1214.

26. Rosai J: Tumors of thyroid gland. In Atlas of Tumor Pathology. Edited by Rosai J, Carcangiu ML, DeLellis RA. Washington: Armed Forces Institute of Pathology; 1992:31-50

27. LiVolsi VA, Baloch ZW: Follicular neoplasms of the thyroid: view, biases, and experiences. Adv Anat Pathol 2004, 11:279-87.

28. Besic N, Hocevar M, Zgajnar J, Petric R, Pilko G: Aggressiveness of therapy and prognosis of patients with Hürthle cell papillary thyroid carcinoma. Thyroid 2006, 16:67-72

29. Sobin LH, Gospodarowicz MK, Wittekind C: Thyroid gland (ICD-O C73). In TNM Classification of Malignant Tumours, 7th Edition. Edited by Sobin LH, Gospodarowicz MK, Witekind C. New York: Wiley Blackwell; 2009:58-62.

30. Schlumberger M, Pacini F: Follow up: Lessons from the past. In Thyroid Tumors. 2nd edition. Paris: Edicions Nucleon; 2003:147-165.

31. Besic N, Auersperg M, Gazic B, Dremelj M, Zagar I: Neoadjuvant chemotherapy in 29 patients with locally advanced follicular or Hürthle cell thyroid carcinoma: a phase 2 study. Thyroid 2012, 22:131-137.

32. Zagar I, Schwarzbartl-Pevec A, Vidergar-Kralj B, Horvat R, Besic N: Recombinant human thyrotropin-aided radioiodine therapy in patients with metastatic differentiated thyroid carcinoma. J Thyroid Res 2012, 2012:670180.

33. Besic N, Zgainar J, Hocevar M, Frkovic-Grazio S: Is patient's age a prognostic factor for follicular thyroid carcinoma in the TNM classification system? Thyroid 2005, 15:439-448.

doi:10.1186/1471-2407-14-777

Cite this article as: Petric et al:: Prognostic factors for disease-specific survival in 108 patients with Hürthle cell thyroid carcinoma: a single-institution experience. BMC Cancer 2014 14:777.

\section{Submit your next manuscript to BioMed Central and take full advantage of:}

- Convenient online submission

- Thorough peer review

- No space constraints or color figure charges

- Immediate publication on acceptance

- Inclusion in PubMed, CAS, Scopus and Google Scholar

- Research which is freely available for redistribution 